\title{
Abordagens bioéticas e deontológicas do novo código de ética profissional para terapeutas ocupacionais no Brasil ${ }^{1}$
}

\author{
Leandro Corrêa Figueiredo ${ }^{a}$, Aline Cristina Martins Gratáo ${ }^{b}$, Tatiana Barcelos Pontes ${ }^{c}$, \\ Emerson Fachin-Martins ${ }^{\mathrm{d}}$
}

\author{
aDepartamento de Fisioterapia, Universidade Federal de São Carlos - UFSCar, São Carlos, SP, Brasil. \\ ${ }^{\text {b}}$ Departamento de Gerontologia, Universidade Federal de São Carlos - UFSCar, São Carlos, SP, Brasil. \\ 'Departamento de Terapia Ocupacional, Universidade de Brasília - UnB, Brasília, DF, Brasil. \\ dDepartamento de Fisioterapia, Universidade de Brasília - UnB, Brasília, DF, Brasil.
}

\begin{abstract}
Resumo: Introdução: Atualmente, os conflitos encontrados no campo da saúde trazem novas discussões sobre ética e bioética também no domínio da Terapia Ocupacional. Como já notado em estudos anteriores, os códigos de ética profissionais não são suficientes para enfrentar os desafios correntes rotineiramente experimentados durante a vida profissional. Objetivo: O presente estudo objetivou encontrar evidências documentais de abordagens deontológicas e bioéticas no novo código brasileiro para terapeutas ocupacionais, por análise de conteúdo comparada à mesma análise no código precedente. Método: Métodos para análise de conteúdo em documentos escritos foram aplicados para revelar as abordagens deontológicas e bioéticas entre os fragmentos textuais obtidos do novo código de ética. Resultados: As abordagens bioéticas estavam aumentadas e mais presentes no total deste código $(53,6 \%)$, considerando a proporção encontrada no código mais antigo. Ao que parece, o aumento foi um resultado da quantidade de fragmentos classificados como relacionados à categoria justiça $(22,6 \%)$, uma das mais evidentes diferenças observadas. Levando-se em conta a razão entre a quantidade total de fragmentos classificados como autonomia do cliente e do profissional no novo código, embora os fragmentos relacionados ao profissional tenham permanecido mais altos em comparação com os fragmentos relacionados ao cliente, uma significativa diminuição dessa razão nas suas porcentagens foi detectada. Conclusão: Em conclusão, a comparação entre os códigos revelou uma incorporação bioética acompanhada de uma prática mais centrada no cliente, a qual reflete a forma de trabalho desde sempre aplicada pelo terapeuta ocupacional.
\end{abstract}

Palavras-chave: Terapia Ocupacional, Teoria Ética, Bioética, Códigos de Ética.

\section{Bioethical and deontological approaches of the new occupational therapy code of ethics in Brazil}

\begin{abstract}
Introduction: Currently, conflicts found in the health field bring new discussions on ethical and bioethical issues also in the Occupational Therapy domain. As noted in previous studies, the codes of professional ethics are not sufficient to face the current challenges daily experienced during professional practice. Objective: The present study aimed to find documental evidence of deontological and bioethical approaches in the new Brazilian code for Occupational Therapists through content analysis compared with the same analysis conducted in the preceding code. Method: Content analysis methods were applied to written documents to reveal deontological and bioethical
\end{abstract}

Autor para correspondência: Tatiana Barcelos Pontes, Faculdade de Ceilândia, Universidade de Brasília, Campus de Ceilândia, QNN 14, Área Especial, CEP 72220-140, Ceilândia Sul, Brasília, DF, Brasil, e-mail: tatianapontes@unb.br

Recebido em Out. 9, 2015; 1 ${ }^{\text {a }}$ Revisão em Dez. 6, 2015; Aceito em Jan. 9, 2016. 
approaches among textual fragments obtained from the new code of ethics. Results: The bioethical approaches found in the totality of the new code were increased in content and number (53.6\%) proportionally compared with those found in the former code. It seems that this increase was a result of the number of fragments classified in the justice-related category (22.6\%) - one of the most evident differences observed. Considering the ratio between the total number of fragments classified as professional autonomy and client autonomy in the new code - although the number of professional-related fragments have remained higher in comparison with client-related fragments - a significant decrease in the percentages of this ratio was detected. Conclusion: In conclusion, comparison between the codes revealed a bioethical embedding accompanied by a more client-centered practice, which reflects the way professionals have always conducted Occupational Therapy practice.

Keywords: Occupational Therapy, Ethical Theory, Bioethics, Code of Ethics.

\section{Introdução}

Apesar de existirem desde a década de 1920, os conceitos de Bioética ganharam impulso a partir do momento em que novos conflitos, tais como os avanços tecnológicos, principalmente nas áreas da Biologia e da Genética, entre outros, fizeram os profissionais da saúde se depararem com novas situaçôes de conflitos da profissão (GOMES; MOURA; AMORIM, 2006; KOERICH; MACHADO; COSTA, 2005; UDELSMANN, 2006).

Apesar de ter sido citada anteriormente, seu marco de expansão é datado de 1971 pelo Dr. Van Raessenlaer Potter com a obra "Bioética: Ponte para o Futuro”, na qual expressa profunda preocupação com a interação das questóes ambientais e de saúde (POTTER, 1971).

Atualmente, a Bioética pode ser definida como

Estudo sistemático das dimensões morais incluindo visão moral, decisões, conduta e políticas - das ciências da vida e atenção à saúde, utilizando uma variedade de metodologias éticas em um cenário interdisciplinar (POST, 2004, p. 12).

Anteriormente aos novos conflitos, assim como em outras profissóes na área da saúde, a conduta do profissional da Terapia Ocupacional era definida pelo Código de Ética Profissional da Fisioterapia e Terapia Ocupacional, deixando as discussóes bioéticas ligadas em um primeiro momento apenas à pesquisa e ciência em saúde. Este Código de Ética surgiu em 1978, anos após a regulamentação destas profissóes e, durante 35 anos, direcionou a conduta dos profissionais de ambas as profissóes - Fisioterapia e Terapia Ocupacional (ANTONIO; FONTES, 2011; CONSELHO..., 1978).

Embora tenham surgido em época próxima, na Terapia Ocupacional notou-se a necessidade de novas discussōes sobre as questóes que envolvem o código de ética e as questóes bioéticas, uma vez que estes códigos mostraram-se insuficientes para nortear as condutas profissionais (ALVES et al., 2007; MACHADO et al., 2007; ZOBOLI; SOARES, 2012).

Em estudo anterior, em que foi analisada a visão bioética do antigo Código de Ética Profissional da Fisioterapia e da Terapia Ocupacional, foi observado que este trazia concepçôes deontológicas corporativistas e legalistas que protegiam mais a autonomia profissional que a do cliente, evidenciando o paternalismo na relação terapeuta-cliente (FIGUEIREDO; GRATÃO; MARTINS, 2013).

Somadas a estes fatores, estão as transformações profissionais e técnico-científicas que a Terapia Ocupacional enfrenta atualmente, uma vez que as Diretrizes Curriculares Nacionais dos cursos na área da saúde surgiram somente a partir do ano de 2002 (ALMEIDA; TREVISAN, 2011; BARBA et al., 2012; BRASIL, 2002).

Esta nova conjuntura levou à reformulação do Código de Ética Profissional da Terapia Ocupacional, que, atualmente apresentado separadamente do Código Profissional da Fisioterapia, permite a possibilidade de aproximação entre as discussóes que envolvem Ética e Bioética à prática profissional. Tais discussões, que deveriam acontecer já na graduação, auxiliam os estudantes uma vez que fazem com que estes se organizem e reflitam sobre o seu futuro comportamento profissional (ALMEIDA; CASTIGLIONI, 2005; CONSELHO..., 2013; MACHADO et al., 2007).

Assim, com a publicação do novo Código de Ética Profissional da Terapia Ocupacional e diante da carência de estudos que envolvam a bioética no campo da Terapia Ocupacional, o objetivo deste trabalho foi identificar em quais proporçóes os conteúdos deontológicos e bioéticos estão presentes neste novo código e compará-los com os conteúdos bioéticos que estavam presentes no antigo código, traçando um perfil epistemológico que poderá subsidiar interpretaçôes da visão de conduta profissional e adequaçôes de forma e linguagem do código. 


\section{Método}

\subsection{Bases teóricas e procedimentais de análise}

O estudo foi delineado em fonte documental para análise interpretativa conforme metodologia descrita por Pyrrho et al. (2009) e Figueiredo, Gratão e Martins (2013). Utiliza comparação do antigo com o novo código de ética.

A análise de conteúdo orientou-se pelo referencial de Bardin (1977). Em suas concepçóes de análise sobre conteúdo, ela afirma que, ao usar métodos quantitativos como técnica de análise qualitativa, a definição de um estudo qualitativo não é contrariada filosófica e estruturalmente. A autora descreve que "[...] a análise de conteúdo é uma técnica de investigação que tem por finalidade a descrição objetiva, sistemática e quantitativa do conteúdo manifesto da comunicação" (BARDIN, 1977, p. 19).

Optou-se pela distribuição das unidades textuais por frequenciamento conforme já descrito, já que esta forma não é excludente ao método de análise de conteúdo (CAMPOS, 2004).

\subsection{Organização das categorias de unidades textuais e processamento}

Cada documento foi fragmentado em unidades textuais que poderiam corresponder a parágrafos, frases ou palavras que expressam um conteúdo com significado textual.

Conforme previamente publicado (FIGUEIREDO; GRATÃO; MARTINS, 2013), as unidades textuais poderiam ser classificadas em uma ou mais de uma das seis categorias resultantes dos quatro princípios bioéticos (autonomia, beneficência, não maleficência e justiça) e da inclusão de duas categorias (virtude e técnica) relacionadas a princípios deontológicos. Observou-se, durante o desenvolvimento do trabalho, que apenas as categorias do principialismo bioético não eram suficientes para categorizar os textos. Para isso, foram inseridas duas categorias que representam em sua concepçáo enfoques deontológicos, podendo assim existir as comparaçóes de enfoques. São elas: virtude (por ser definida como a categoria que sugere a valorização da honra, prestígio e tradição profissional) (PURTILO, 2000) e técnica (por ser a categoria que expressa conteúdo prescritivo do profissional) (PYRRHO et al., 2009).

Também como em estudo anterior (FIGUEIREDO; GRATÁO; MARTINS, 2013), a categoria autonomia foi subdividida em outras duas categorias: autonomia profissional e autonomia do cliente, a depender de quem era beneficiário da conduta moral.

Da mesma forma, para cada categoria definida, incluindo a subdivisão da categoria autonomia, foi criada uma coluna organizada de forma matricial em um total de sete colunas na planilha do aplicativo Excel, sendo que cada linha desta matriz indica uma página do documento analisado.

Para se calcular por soma o total de unidades textuais de maneira organizada, após marcação feita no texto impresso, a quantidade de unidades textuais foi inserida na célula de cruzamento correspondente à página (linha) em que foi identificada para a categoria (coluna) em que foi classificada.

Além da distribuição de frequência das unidades textuais, também foram calculadas as proporçôes observadas no novo código em relação às proporçôes esperadas, tendo como base o antigo código de ética. Diferenças entre proporçôes foram detectadas pelo teste Quiquadrado, considerando diferenças significativas aquelas em que foi obtido valor de $\mathrm{p}<0,05$.

\section{Resultados}

O Novo Código de Ética Profissional da Terapia Ocupacional apresentou quase o dobro de unidades textuais quando comparado ao antigo código, sendo observadas agora 239 unidades textuais, ou seja, um aumento de mais 120 unidades textuais identificadas (Tabela 1).

No antigo código, as 54 unidades identificadas como pertencentes às categorias do principialismo bioético foram superadas pelas unidades textuais classificadas como pertencentes às categorias deontológicas que somaram 64 unidades textuais (Tabela 1).

Já no novo código ocorreu uma inversão, as unidades classificadas como pertencentes às categorias do principialismo bioético (128 unidades) ultrapassaram a soma das unidades identificadas como deontológicas (111 unidades).

Apesar do predomínio de unidades relacionadas ao principialismo bioético, que superou os conteúdos deontológicos em 3,6\% (Figura 1), a Tabela 1 mostra ainda que a ordem decrescente de quantidade de unidades textuais por categoria no antigo código quase se manteve no novo código, apresentando mudanças apenas nas categorias justiça (agora a segunda mais encontrada com $22,6 \%$ do total) e beneficência (deixa de ser a menos encontrada com $6,3 \%$ do total de unidades textuais). O predomínio de conteúdos presentes na categoria virtude, relacionada à deontologia, continuou sendo 
Tabela 1. Distribuição de frequência em valores absolutos de unidades textuais localizadas e categorizadas por documento.

\begin{tabular}{lllc|c}
\hline & & \multicolumn{2}{c}{ Novo } & Antigo \\
\hline & Justiça & 54 & 21 \\
\cline { 2 - 5 } Principialismo Bioético & Beneficência & 15 & 04 \\
\cline { 2 - 5 } & Não maleficência & 17 & 10 \\
\cline { 2 - 5 } & \multirow{2}{*}{ Autonomia } & Profissional & 28 & 13 \\
\cline { 2 - 5 } & Cliente & 14 & 06 \\
\hline \multirow{2}{*}{ Deontologia } & Virtude & 67 & 38 \\
\cline { 2 - 5 } & Técnica & 44 & 26 \\
\hline Total & & 239 & 118 \\
\hline Astay
\end{tabular}

As categorias com mais e menos unidades textuais foram destacadas em caixas na tabela.

\section{Novo Código de Ética e Deontologia da Terapia Ocupacional}

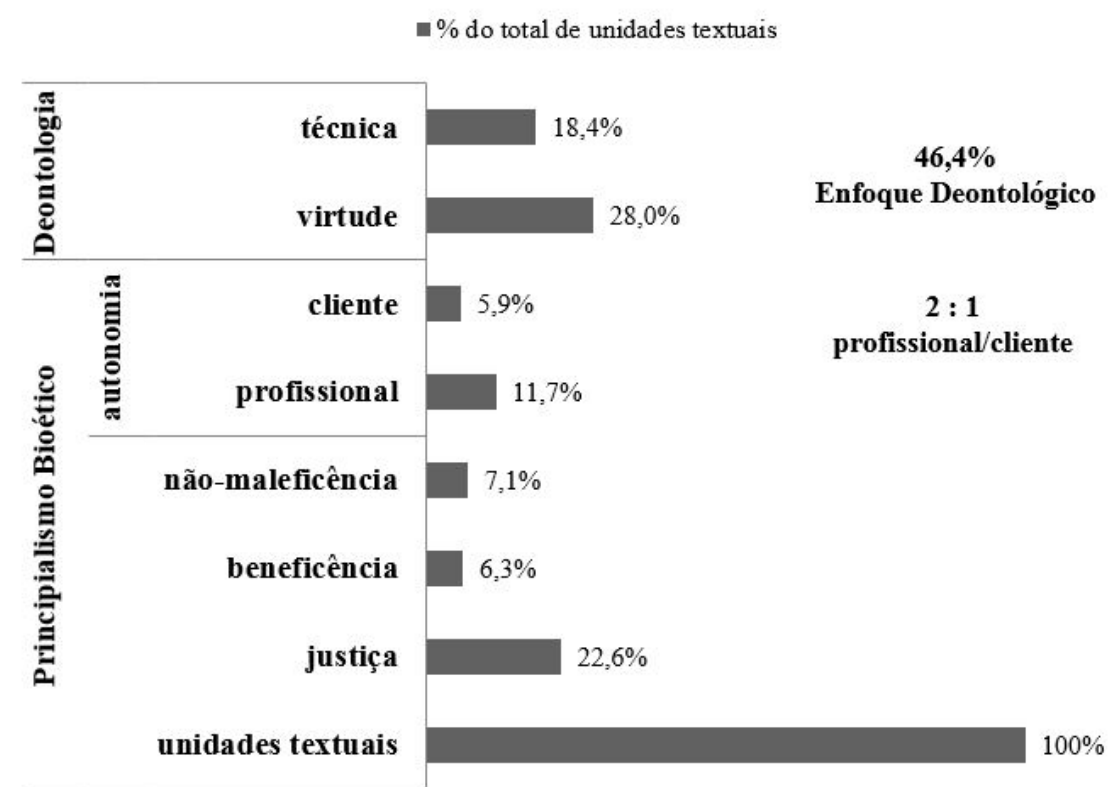

Figura 1. Distribuição de frequência das unidades textuais totais por categoria e conteúdos deontológicos (técnica e virtude) ou bioéticos (autonomia, não maleficência, beneficência e justiça) no Novo Código de Ética e Deontologia da Terapia Ocupacional. À direita do histograma encontra-se o total em porcentagem de unidades textuais classificadas como de conteúdo deontológico, bem como a razão de proporcionalidade entre as unidades textuais subdividas entre autonomia profissional ou do cliente.

o mais prevalente, com 67 e 38 unidades no novo e antigo código, respectivamente (Tabela 1).

Modificaçôes nesta ordem foram observadas somente com relação à categoria justiça do principialismo bioético (54 unidades) que superou a categoria deontológica relacionada à técnica (44 unidades), seguida pela categoria beneficência, que era menos prevalente no antigo código e passou a superar a categoria autonomia do cliente no novo código. Verificou-se que a categoria autonomia do cliente, que estava em penúltimo lugar no código antigo, passou a última no código novo.
A Figura 1 aponta, ainda, que os enfoques deontológicos no novo código representaram $46,4 \%$ do total de unidades textuais e uma proporçáo de 2 unidades textuais com conteúdo categorizado como autonomia profissional para cada unidade textual categorizada como autonomia do cliente $(2: 1)$.

Do total de unidades textuais categorizadas nos dois códigos, $67 \%$ foram identificadas no novo código. $\mathrm{O}$ código antigo era organizado em 6 capítulos, o novo código passou a ser organizado em 11 capítulos, dos quais, 5 são capítulos abordando novos temas, sendo: Disposiçóes Preliminares, Do Relacionamento com o Cliente/Paciente/Usuário, Do sigilo Profissional, 


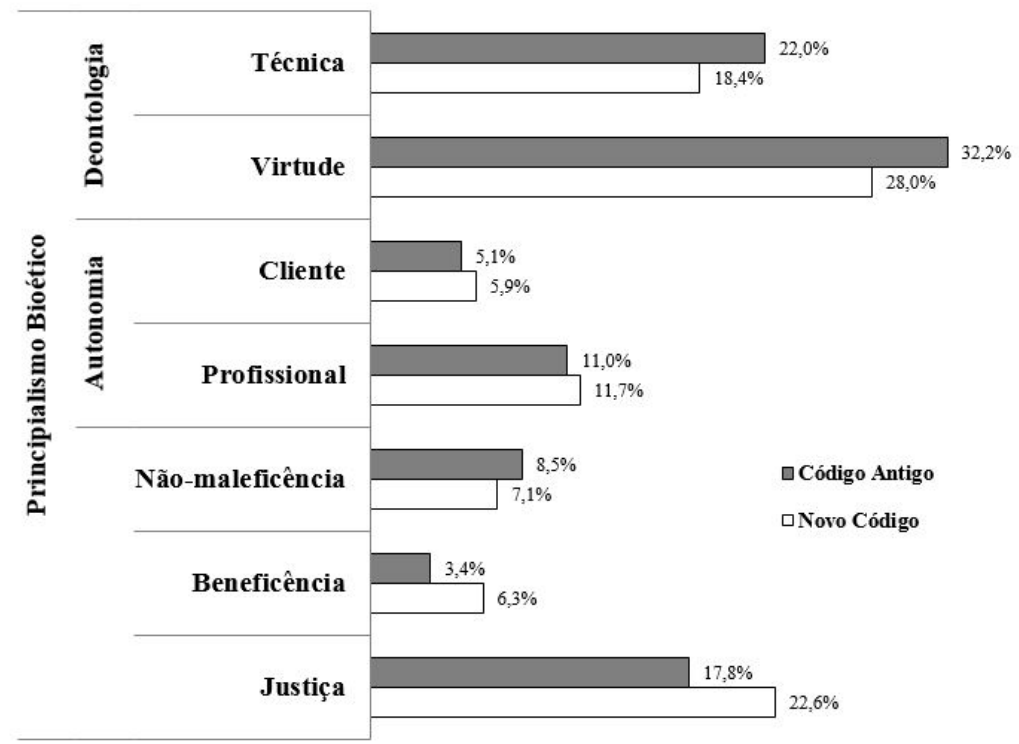

Figura 2. Comparações das proporções da distribuição de frequência das unidades textuais totais por categoria e conteúdos deontológicos (técnica e virtude) ou bioéticos (autonomia, não maleficência, beneficência e justiça) nos textos bioéticos. A barra cinza indica as porcentagens obtidas no código de ética antigo e as barras brancas indicam as proporções para as mesmas categorias obtidas no novo código de ética.

Da Docência, Preceptoria, da Pesquisa e Produção Científica e da Divulgação Profissional.

Ao compararmos as porcentagens de unidades textuais entre os códigos (Figura 2), observa-se aumento relativo nas categorias autonomia, tanto profissional quanto do cliente, beneficência e justiça; sendo observada redução relativa nas demais.

Apesar dos aumentos e reduçóes relativas observadas na Figura 2, a proporção esperada com base no antigo código não se modificou significativamente da proporção observada no novo código pela análise do teste Quiquadrado ( $\mathrm{p}>0,05)$.

Ao analisar separadamente somente a proporção de unidades textuais informando autonomia profissional e do cliente (Figura 3), foi possível identificar uma redução significativa $(\mathrm{p}<0,05)$ no novo código de $1,7 \%$ para as unidades textuais relacionadas à autonomia profissional e aumento também significativo de 1,7\% para unidades textuais relacionadas à autonomia do cliente. Entretanto, essas diferenças não impediram que a categoria autonomia do cliente fosse a menos predominante em conteúdos no novo código de ética.

\section{Discussão}

Apesar de não ter apresentado grandes modificaçóes em seu novo conteúdo, o novo Código de Ética da Terapia Ocupacional aponta alguns avanços nas questóes bioéticas, observados principalmente

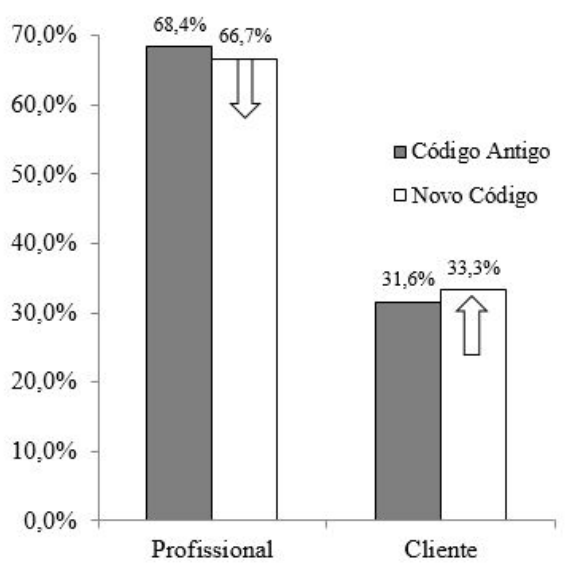

Figura 3. Gráfico de barras indicando a comparação das proporções de unidades textuais categorizadas em autonomia do profissional ou cliente para o antigo (cinza) e novo (branca) código de ética. O teste Quiquadrado detectou diferenças significativas entre proporções $(\mathrm{p}<0,05)$ quando analisadas em separado das demais categorias analisadas. A seta apontando para baixo indica redução no novo código de ética e a seta para cima indica aumento neste mesmo código.

pela maior presença de categorias relacionadas ao principialismo bioético, sendo possível neste novo código observar todas as unidades textuais (beneficência, não maleficência, justiça e autonomia) 
distribuídas de forma clara no texto, enquanto no antigo código apenas a categoria autonomia era citada de forma clara e seguida do predomínio da palavra profissional (CONSELHO..., 1978, 2013).

Diferente do antigo código, no qual virtude e técnica, que possuem referencial deontológico, eram os itens mais citados, no novo código o item justiça aparece logo atrás do item virtude. A justiça representa a distribuição coerente e adequada de deveres e benefícios sociais, item em destaque nas Diretrizes Curriculares Nacionais para o curso de Terapia Ocupacional (BISPO JÚNIOR, 2010; BRASIL, 2002).

Além disso, a justiça é o princípio formal da equidade, um dos princípios doutrinários estabelecidos no Sistema Único de Saúde - SUS (KOERICH; MACHADO; COSTA, 2005; MUÑOZ, 2004).

Com isso, e por se tratar de uma profissão que prioriza as atividades e ocupaçôes significativas do indivíduo, como uma oportunidade para promoção e participação social, a educação realizada a partir deste novo código pode aproximar as questôes bioéticas da prática profissional (ALMEIDA; TREVISAN, 2011), já que atualmente pesquisas apontam para uma educaçáo ainda pautada na arrogância pessoal e necessidade do poder, que expõem dificuldades para encontrar soluções diante dos conflitos (SANTANA et al., 2009).

No item autonomia, ainda que tenha reduzido a proporção, prevaleceu a autonomia profissional sobre a autonomia do cliente. Tal fato mostra a dimensão autoritária muitas vezes chamada de paternalismo que caracteriza o terapeuta como o lado mais forte da relação (SILVA, 2010).

Esta não é uma particularidade da Terapia Ocupacional, já que Koerich e Erdmann (2011) em pesquisa em banco de teses, observaram que os temas que envolvem educação em saúde, quando aplicados na resolução de problemas cotidianos junto a usuários de saúde, revelaram condutas profissionais autoritárias e paternalistas.

Esse autoritarismo vai na contramão das propostas de Almeida e Trevisan (2011) que definem o papel do Terapeuta Ocupacional como facilitador da ação, com o foco voltado para o cliente, respeitando suas necessidades individuais. Além de ser contrário às perspectivas internacionais, como apresentado pelo código de ética da Associação Canadense de Terapia Ocupacional, que identifica como competência essencial do terapeuta ocupacional habilitar o cliente a participar ativamente durante a negociação de objetivos, sendo suas necessidades e metas consideradas prioritárias e colocadas como centro da avaliaçáo, intervenção e resultados esperados.

Essa visão da Terapia Ocupacional com foco voltado para o cliente é reforçada pelos autores que definem a prática do Terapeuta Ocupacional como possuidor de tecnologias e conhecimento para emancipação e autonomia do cliente (BARROS; LOPES; GALHEIGO, 2002; CARVALHO, 2012).

Cohen (2008) e Barba et al. (2012) propóem que devem existir mudanças na formação na área da Saúde e em Terapia Ocupacional, aproximando estes profissionais das situaçôes de conflito por meio de simulados e afastando-se da educaçấo tradicional que expõe dificuldades na formação destes profissionais quanto às relaçóes terapeuta/paciente. Entretanto, a maior dificuldade ainda é encontrada na baixa oferta de profissionais e disciplinas que promovam a discussão entre conceitos deontológicos e bioéticos, assim como nas discussóes filosóficas que envolvem o assunto (FURLAN et al., 2014; ALVES et al., 2008; BARBA et al., 2012; COHEN, 2008; FIGUEIREDO, 2011; POULIS, 2007).

A nova organização do código profissional possui um dos 11 capítulos voltados para as discussóes de relacionamento entre terapeuta/cliente, apesar de também contemplar novos conteúdos deontológicos como, a exemplo, o capítulo "Da Divulgação Profissional".

A partir do conceito de formaçáo contínua em bioética, que considera o pluralismo moral dos usuários de saúde e trabalhadores, descrito por Zoboli e Soares (2012), acredita-se que a aproximação destes conteúdos bioéticos no novo Código de Ética, mesmo que de forma discreta, pode auxiliar e representar avanço na resolução de conflitos entre terapeuta/paciente.

Os resultados apontaram também que a beneficência deixa de ser a unidade textual menos citada, permanecendo com poucas citaçóes, apesar de ser o princípio que melhor representa o papel do profissional e das instituiçóes diante do cliente (PYRRHO et al., 2009; SOUZA et al., 2013). A partir da mudança na educação em relação aos conflitos discutidos anteriormente, propóe-se que, a partir deste novo código, agora pouco mais próximo das questóes bioéticas, a beneficência deixe de ser discutida como caráter ético de dever que sobrepóe a autonomia do cliente e passe a respeitá-lo como detentor do direito de escolha junto ao profissional, devendo haver consenso entre as partes (SILVA, 2010).

Já o princípio da não maleficência, reconhecido como o dever do profissional em não causar danos ou diminuir os riscos ao cliente, continua sendo pouco citado, ainda sustentado pela ideia de que não 
se espera conduta contrária a essa do profissional de saúde (KOERICH; MACHADO; COSTA, 2005; SOUZA et al., 2013).

Depois de finalizada as análises sobre os conteúdos deontológicos e aquelas referentes aos conceitos bioéticos, outra observação importante foi feita no novo código, a visão de atuação do profissional também voltada para o sistema público de saúde. A presença de capítulos como "Do relacionamento Cliente/Paciente/ Usuário”, presentes no novo código, concretiza a interdisciplinaridade e ressalta os aspectos relativos à humanização do cuidado, proposta no Sistema Único de Saúde (SUS). Observa-se que os desafios não estão apenas na inserção do profissional no SUS, mas também na capacitação desse profissional para o trabalho no SUS (FURLAN et al., 2014). Por isso, espera-se que, a partir do momento que o novo código traz estas questôes para serem debatidas, ocorrerá melhora gradual sobre este assunto na educação destes profissionais. Não foram percebidas informaçôes relativas às outras esferas de atuação da terapia ocupacional, como campo social e educação; entretanto, destaca-se o aumento na citação de conceitos como justiça, participação, inclusão social e discriminação.

\section{Conclusão}

Conclui-se que, apesar de leves nas proporçôes, houve mudanças no novo código que o aproxima das questôes bioéticas, principalmente daquelas voltadas para a justiça e autonomia do profissional. Essas questôes devem ser debatidas de forma mais profunda pelos estudiosos da área e difundidas aos estudantes de graduação em Terapia Ocupacional por meio teórico e prático, a fim de aproximá-los dos conflitos éticos presentes na prática profissional.

\section{Referências}

ALMEIDA, D. T. D.; TREVISAN, É. R. Estratégias de intervençáo da Terapia Ocupacional em consonância com as transformaçốes da assistência em saúde mental no Brasil. Interface - Comunicação, Saúde, Educação, Botucatu, v. 15, n. 36, p. 299-308, 2011.

ALMEIDA, M. H. M. D.; CASTIGLIONI, M. D. C. O ensino da ética ao profissional de saúde na USP: a formação ética do terapeuta ocupacional. Revista de Terapia Ocupacional da USP, São Paulo, v. 16, n. 2, p. 75-81, 2005.

ALVES, F. D. et al. O preparo bioético na graduação de Fisioterapia. Fisioterapia e Pesquisa, São Paulo, v. 15, n. 2, p. 149-156, 2008.

ALVES, F. J. D. S. et al. Um estudo empírico sobre a importância do código de ética profissional para o con- tabilista. Revista Contabilidade e Finanças, São Paulo, v. 18, n. 43, p. 58-68, 2007.

ANTONIO, E. M. R.; FONTES, T. M. P. A ética médica sob o viés da bioética: o exercício moral da cirurgia. Revista do Colégio Brasileiro de Cirurgióes, Rio de Janeiro, v. 38, n. 5, p. 355-360, 2011.

BARBA, P. C. D. S. D. et al. Formação inovadora em Terapia Ocupacional. Interface - Comunicação, Saúde, Educação, Botucatu, v. 16, n. 42, p. 829-842, 2012.

BARDIN, L. Análise de conteúdo. Lisboa: Ediçōes 70, 1977.

BARROS, D. D.; LOPES, R. E.; GALHEIGO, S. M. Projeto Metuia-Terapia Ocupacional no campo social. O Mundo da Saúde, São Paulo, v. 26, n. 3, p. 365-369, 2002.

BISPO JÚNIOR, J. P. Fisioterapia e saúde coletiva: desafios e novas responsabilidades profissionais. Ciências e Saúde Coletiva, Rio de Janeiro, v. 15, n. 1, p. 1627-1636, 2010.

BRASIL. Conselho Nacional de Educação. Câmara de Educação Superior. Resolução CNE/CES no 6, 19 de fevereiro de 2002. Institui Diretrizes Curriculares Nacionais do Curso de Graduaçáo em Terapia Ocupacional. Diário Oficial [da] República Federativa do Brasil, Brasília, DF, 4 mar. 2002.

CAMPOS, C. J. G. Método de análise de conteúdo: ferramenta para a análise de dados qualitativos no campo da saúde. Revista Brasileira de Enfermagem, Brasília, v. 57, n. 5, p. 611-614, 2004

CARVALHO, C. R. A. D. A identidade profissional dos terapeutas ocupacionais: consideraçôes a partir do conceito de estigma de Erving Goffman. Saúde e Sociedade, São Paulo, v. 21, n. 2, p. 364-371, 2012.

COHEN, C. Por que pensar a bioética? Revista da Associação Médica Brasileira, São Paulo, v. 54, n. 6, p. 473474, 2008.

CONSELHO FEDERAL DE FISIOTERAPIA E TERAPIA OCUPACIONAOL - COFFITO. Resolução $\mathrm{n}^{\circ} 10$, de 3 de julho de 1978. Código de Ética Profissional de Fisioterapia e Terapia Ocuacional. Diário Oficial [da] República Federativa do Brasil, Brasília, DF, 22 set. 1978.

CONSELHO FEDERAL DE FISIOTERAPIA E TERAPIA OCUPACIONAOL - COFFITO. Resolução n²525, de 8 de julho de 2013. Estabelece o Código de Ética e Deontologia da Terapia Ocupacional. Diário Ofcial [da] República Federativa do Brasil, Brasília, DF, 1 ago. 2013

FIGUEIREDO, A. M. D. Perfil acadêmico dos professores de bioética nos cursos de pós-graduação no Brasil. Revista Brasileira de Educação Médica, Rio de Janeiro, v. 35, n. 2, p. 163-170, 2011

FIGUEIREDO, L. C.; GRATÃO, A. C. M.; MARTINS, E. F. Código de ética para fisioterapeutas e te- 
rapeutas ocupacionais revela conteúdos relacionados à autonomia do profissional. Fisioterapia e Pesquisa, São Paulo, v. 20. n. 4, p. 394-400, 2013.

FURLAN, P. G. et al. Formação profissional de terapeutas ocupacionais e o curso de graduação da Universidade de Brasília, Faculdade de Ceilândia. Cadernos de Terapia Ocupacional da UFSCar, São Carlos, v. 22, n. 1, p. 109119, 2014.

GOMES, A. M. D. A.; MOURA, E. R. F.; AMORIM, R. F. O lugar da ética e bioética nos currículos de formaçáo médica. The place of ethics and bioethics in medical education. Revista Brasileira de Educação Médica, Rio de Janeiro, v. 30, n. 2, p. 56-65, 2006.

KOERICH, M. S.; ERDMANN, A. L. O Estado da Arte sobre ética em saúde no Brasil: pesquisa em banco de teses. Texto \& Contexto - Enfermagem, Florianópolis, v. 20, n. 3, p. 576-584, 2011.

KOERICH, M. S.; MACHADO, R. R.; COSTA, E. Ética e bioética: para dar início à reflexão. Texto \& Contexto - Enfermagem, Florianópolis, v. 14, n. 1, p. 106110, 2005.

MACHADO, D. et al. A formação ética do fisioterapeuta. Fisioterapia em Movimento, Curitiba, v. 20, n. 3, p. 101-105, 2007.

MUÑOZ, D. R. Bioética: a mudança da postura ética. Revista Brasileira de Otorrinolaringologia, São Paulo, v. 70, n. 2, p. 578-579, 2004.

POST, S. G. Encyclopedia of Bioethics: IM. New York: MacMillan, 2004.
POTTER, V. R. Bioethics: bridge to the future. New Jersey: Englewood Cliffs, 1971.

POULIS, I. Bioethics and physiotherapy. Journal of Medical Ethics, Londres, v. 33, n. 8, p. 435-436, 2007.

PURTILO, R. B. A time to harvest, a time to sow: ethics for a shifting landscape. Physical Therapy, Washington, v. 80, n. 11, p. 1112-1119, 2000.

PYRRHO, M. et al. Análise bioética do Código de Ética Odontológica brasileiro. Ciência \& Saúde Coletiva, Rio de Janeiro, v. 14, n. 5, p. 1911-1918, 2009.

SANTANA, C. D. S. et al. Reflexões sobre a prática de tutoria com estudantes de terapia ocupacional. Trabalho, Educação e Saúde, Rio de Janeiro, v. 7, n. 1, p. 167-182, 2009.

SILVA, H. B. E. Beneficência e paternalismo médico. Revista Brasileira de Saúde Materno Infantil, Recife, v. 10, n. 2, p. 419-425, 2010.

SOUZA, L. A. F. et al. O modelo bioético principialista aplicado no manejo da dor. Revista Gaúcha de Enfermagem, Porto Alegre, v. 34, n. 1, p. 187-195, 2013.

UDELSMANN, A. Bioética: aspectos de interesse do anestesiologista. Revista Brasileira de Anestesiologia, Rio de Janeiro, v. 56, n. 3, p. 325-333, 2006.

ZOBOLI, E. L. C. P.; SOARES, F. A. C. Capacitação em bioética para profissionais da Saúde da Família do município de Santo André, SP. Revista da Escola de Enfermagem da USP, São Paulo, v. 46, n. 5, p. 1248-1253, 2012.

\section{Contribuição dos Autores}

Leandro Corrêa Figueiredo foi mentor e participou na fundamentação teórica, interpretação dos textos e classificação das unidades textuais. Leandro Corrêa Figueiredo e Aline Cristina Martins Gratão participaram da interpretaçáo dos textos e classificação das unidades textuais. Tatiana Barcelos Pontes participou da fundamentação teórica na perspectiva da terapia ocupacional, da revisão e correção de texto, bem como de orientaçóes durante o processo de processamento e análise dos dados. Emerson Fachin-Martins participou da idealização e da fundamentaçáo teórica e metodológica da proposta, do processamento e análise dos resultados, bem como da revisáo e correçáo de texto. Todos os autores aprovaram a versão final do texto.

\section{Notas}

${ }^{1}$ Parte das reflexóes aqui apresentadas compóe a dissertação de mestrado Abordagens bioéticas e deontológicas do código de ética profissional para fisioterapeutas e terapeutas ocupacionais no Brasil, defendida por Leandro Corrêa Figueiredo no Programa de Pós-graduação Ciências e Tecnologias em Saúde da Universidade de Brasília (UnB). 